A C T A C H E M I C A S C A N D I N A V I C A $24 \quad(1970) \quad 211-220$

\title{
The Crystal Structure of Bis(triphenylsilyl) chromate
}

\author{
BIRGITTA STENSLAND and PEDER KIERKEGAARD
}

Institute of Inorganic and Physical Chemistry, University of Stockholm, Stockholm, Sweden

The crystal structure of bis(triphenylsilyl)chromate, $\left(\left(\mathrm{C}_{6} \mathrm{H}_{5}\right)_{3} \mathrm{Si}\right)_{2} \mathrm{CrO}_{4}$, has been determined from three-dimensional $\mathrm{X}$-ray film data and refined by three-dimensional Fourier methods and leastsquares techniques. The structure is monoclinic, space group $P 2_{1} / b$. The elementary cell contains four formula units and has the dimensions:

$$
\begin{aligned}
& a=11.536 \pm 4 \AA \\
& b=17.394 \pm 5 \AA \\
& c=16.113 \pm 5 \AA \\
& \gamma=96.51^{\circ} \pm 2
\end{aligned}
$$

The crystals are built up of molecules, each of which is formed by a $\mathrm{CrO}_{4}$ tetrahedron which is linked to the silicon atoms by oxygen bridges. In addition to the oxygen contact each silicon atom is also in contact with three aromatic rings which project from it like propeller blades.

\footnotetext{
M
} etal organo-silyl esters with the general formula, $\left[R_{1} R_{2} R_{3} \mathrm{SiO}_{x} M_{y} \mathrm{O}_{z-x}\right.$ where $R_{1}, R_{2}$, and $R_{3}$ are alkyl, aryl, aralkyl, or heterocyclic radicals and where $M$ is chromium(VI), molybdenum(VI), wolfram(VI), or vanadium(V) have been reported ${ }^{1}$ to be good corrosion inhibitors. Especially the compound bis(triphenylsilyl)chromate, is cited as having shown superior ability to inhibit corrosion and also as being more stable than the comparable carbon compound. The present article will give a description of an X-ray investigation of the structure of bis(triphenylsilyl)chromate, $\left[\left(\mathrm{C}_{6} \mathrm{H}_{5}\right)_{3} \mathrm{Si}_{2} \mathrm{CrO}_{4}\right.$.

From a crystalline preparation, kindly supplied by Drs. C. Hare, R. N. Hammer and J. B. Kinsinger of the Michigan State University, unregular shaped orange coloured single crystals were obtained.

\section{X-RAY DIFFRACTION DATA AND COMPUTING METHODS}

The powder pattern of $\left[\left(\mathrm{C}_{6} \mathrm{H}_{5}\right)_{3} \mathrm{Si}_{2} \mathrm{CrO}_{4}\right.$ was completely indexed on the basis of a monoclinic unit cell. The cell parameters were calculated from a photograph taken with strictly monochromatized $\mathrm{Cu} K \alpha_{1}$ radiation $(\lambda=1.54050$ $\AA$ ) in a focusing camera of the Guinier-Hägg type. Potassium chloride

Acta Chem. Scand. 24 (1970) No. 1 
Table 1. X-ray powder data for $\left[\left(\mathrm{C}_{6} \mathrm{H}_{6}\right)_{3} \mathrm{Si}\right]_{2} \mathrm{CrO}_{4} \cdot \mathrm{CuK \alpha}$ radiation. $\lambda\left(\mathrm{CuK} \alpha_{1}\right)=1.54050 \AA$.

\begin{tabular}{|c|c|c|c|}
\hline$h k l$ & $\begin{array}{c}10^{5} \sin ^{2} \theta \\
\text { obs }\end{array}$ & $\begin{array}{c}10^{6} \sin ^{2} \theta \\
\text { calo }\end{array}$ & $I_{\text {obs }}$ \\
\hline 011 & 432 & 427 & $\mathbf{w}$ \\
\hline 101 & 680 & 681 & $\mathrm{~m}$ \\
\hline 020 & 793 & 795 & $\mathrm{~m}$ \\
\hline 002 & 919 & 915 & $\mathrm{~m}$ \\
\hline 021 & 1026 & 1024 & $\mathrm{~m}$ \\
\hline 121 & 1341 & 1341 & $\mathrm{~m}$ \\
\hline 022 & 1718 & 1711 & $\mathrm{~m}$ \\
\hline 122 & - & 2088 & - \\
\hline 201 & 2039 & 2038 & $\mathrm{~m}$ \\
\hline 013 & - & 2259 & - \\
\hline 131 & 2268 & 2268 & $\mathrm{~m}$ \\
\hline 032 & - & 2706 & - \\
\hline 202 & 2718 & 2725 & $\mathrm{~m}$ \\
\hline 113 & 2784 & 2779 & $\mathrm{vw}$ \\
\hline$\overline{2} 12$ & - & 2788 & - \\
\hline 023 & 2854 & 2856 & vw \\
\hline$\overline{1} 32$ & 2959 & 2955 & vst \\
\hline 212 & 3055 & 3060 & vst \\
\hline 123 & - & 3172 & - \\
\hline 040 & 3182 & 3183 & $\mathrm{~m}$ \\
\hline$\overline{2} 22$ & 3241 & 3249 & vVw \\
\hline 132 & - & 3363 & - \\
\hline$\overline{1} 40$ & 3373 & 3364 & vvw \\
\hline 141 & 3598 & 3593 & $\mathrm{~m}$ \\
\hline 004 & 3673 & 3662 & $\mathbf{w}$ \\
\hline 222 & 3787 & 3793 & $\mathbf{w}$ \\
\hline$\overline{2} 13$ & 3934 & 3932 & vw \\
\hline 300 & 4082 & 4071 & $\mathrm{~m}$ \\
\hline$\overline{3} 11$ & - & 4295 & - \\
\hline 301 & 4307 & 4300 & $\mathrm{~m}$ \\
\hline 114 & - & 4382 & - \\
\hline 223 & 4397 & 4393 & $\mathbf{w}$ \\
\hline 133 & 4508 & 4507 & $\mathbf{w}$ \\
\hline$\overline{3} 21$ & 4694 & 4688 & $\mathrm{w}$ \\
\hline
\end{tabular}

The powder photograph was measured and interpreted up to $\sin ^{2} \theta=0.17$. Reflections systematically absent in space group $P 2_{1} / b$ have been omitted.

$(a=6.29228 \AA)^{2}$ was used as an internal standard. Least-squares refinement gave the following unit-cell dimensions (see Table 1) at $25^{\circ} \mathrm{C}$ :

$$
\begin{aligned}
& a=11.536 \pm 4 \AA \\
& b=17.394 \pm 5 \AA \\
& c=16.113 \pm 5 \AA \\
& \gamma=96.51^{\circ} \pm 2 \\
& V=3212 \AA^{3}
\end{aligned}
$$

The theoretical value of the density based on four formula units in the unit cell is $1.32 \mathrm{~g} / \mathrm{cm}^{3}$.

Rotation and Weissenberg photographs $(0 k l-5 k l, h 0 l-h 9 l)$ of two single crystals (rotation axes $a$ and $b$, respectively) were taken with $\mathrm{Cu} K \alpha$ radiation. 
To prevent the slow decomposition of the compound when exposed to daylight the crystals were kept in darkness also during the $\mathrm{X}$-ray examination. The reflections systematically absent in the photographs are $h k 0$ with $k=2 n+1$ and $00 l$ with $l=2 n+1$, which is characteristic of the space group $P 2_{1} / b$.

The reflections were recorded photographically with the multiple film technique. The relative intensities were estimated visually by comparison with an intensity scale obtained by photographic recording of a reflection with different exposure times. A total of 710 independent reflections of nonzero intensity were measured.

The computational work involved in the refinement of lattice constants (Program Pirum ${ }^{3}$ ), correction absorption (No. 6019) and for Lorentz-polarization effects (No. 6024), scaling of reflections recorded from different crystals (Program SFALE ${ }^{4}$ ), Fourier summation (No. 6015), least-squares refinement (block diagonal matrix approximation, isotropic temperature factors, No. 6023), least-squares refinement of rigid groups (full matrix calculation ${ }^{5}$ ), and calculation of interatomic distances (Program DIST ${ }^{6}$ ) was performed on the electronic computers CD 3600 , IBM 1800 or IBM 7090. (The program numbers refer to the world list of crystallographic computer programs ${ }^{7}$ ).

A linear absorption coefficient $\mu=40.3 \mathrm{~cm}^{-1}$ was used in the calculation of the absorption factor for each reflection.

\section{STRUCTURE DETERMINATION}

From the three-dimensional Patterson function approximate parameter values were derived for the four chromium and the eight silicon atoms (situated in point pusitions $\left.4(e): \pm(x y z) ; \pm\left(x, \frac{1}{2}+y, \frac{1}{2}-z\right)\right)$. Three-dimensional electron density calculations were then performed, using the signs of the observed structure factors derived from the chromium and silicon contributions only. (In this and subsequent calculations atomic scattering curves for $\mathrm{Cr}^{3+}$ and un-ionized silicon, oxygen, and carbon atoms were used. The real part of the anomalous dispersion correction ${ }^{8}$ was applied to the scattering curves ${ }^{9}$ ). In addition to the $\mathrm{Cr}$ and $\mathrm{Si}$ atoms the Fourier maps thus obtained also showed the positions of the sixteen oxygen atoms occupying four sets of $4(e)$ point positions. From subsequent three-dimensional calculations approximate positions of the twentyfour aromatic rings were deduced.

A refinement of the coordinates so obtained was then performed using a least-squares block diagonal matrix program with isotropic temperature factors for all of the atoms refined, viz. chromium, silicon, oxygen, and carbon. Including the scale factors, a total of 181 parameters were involved in the refinement which, in comparison with the total number of independent reflections, only gives an over-determination by a factor of about four. Therefore, a complete refinement by means of this method was possible to reduce the index discrepancy index $R$, defined in the usual way, from, initially, 0.44 to 0.14 . From this result and since the interatomic distances based on the coordinates obtained, from the last cycle were found to be of reasonable lengths, it was concluded that the atomic parameters arrived at were likely to represent an adequate description of the architecture of the structure, which was the primary interest of this investigation.

Acta Chem. Scand. 24 (1970) No. 1 
Table 2. Atomic coordinates for $\left[\left(\mathrm{C}_{6} \mathrm{H}_{5}\right)_{3} \mathrm{Si}_{2} \mathrm{CrO}_{4}\right.$.

\begin{tabular}{|c|c|c|c|c|}
\hline Atom & $x \pm \sigma(x)$ & $y \pm \sigma(y)$ & $z \pm \sigma(z)$ & $B \pm \sigma(B) \AA^{2}$ \\
\hline $\mathrm{Cr}$ & $0.8260 \pm 3$ & $0.5591 \pm 2$ & $0.8474 \pm 2$ & $5.68 \pm 10$ \\
\hline Sil & $0.6171 \pm 4$ & $0.4861 \pm 2$ & $0.7416 \pm 3$ & $3.71 \pm 12$ \\
\hline $\mathrm{Si} 2$ & $1.0480 \pm 4$ & $0.6289 \pm 2$ & $0.7331 \pm 3$ & $3.64 \pm 13$ \\
\hline 01 & $0.7350 \pm 9$ & $0.4856 \pm 5$ & $0.7939 \pm 6$ & $5.36 \pm 25$ \\
\hline $\mathrm{O} 2$ & $0.9287 \pm 9$ & $0.6050 \pm 5$ & $0.7828 \pm 6$ & $5.66 \pm 27$ \\
\hline $\mathrm{O3}$ & $0.8895 \pm 10$ & $0.5203 \pm 7$ & $0.9196 \pm 7$ & $8.65 \pm 34$ \\
\hline $\mathrm{O4}$ & $0.7476 \pm 11$ & $0.6144 \pm 7$ & $0.8843 \pm 8$ & $10.84 \pm 39$ \\
\hline Cll & $0.3694 \pm 6$ & $0.5811 \pm 4$ & $0.3498 \pm 4$ & $6.77 \pm 22$ \\
\hline C12 & 0.3070 & 0.6439 & 0.3372 & \\
\hline C13 & 0.3022 & 0.6989 & 0.3994 & \\
\hline Cl4 & 0.3598 & 0.6910 & 0.4742 & \\
\hline C15 & 0.4223 & 0.6282 & 0.4868 & \\
\hline Cl6 & 0.4271 & 0.5732 & 0.4246 & \\
\hline C21 & $0.3982 \pm 6$ & $0.2592 \pm 4$ & $0.3546 \pm 4$ & $6.31 \pm 22$ \\
\hline $\mathrm{C} 22$ & 0.4828 & 0.2911 & 0.2993 & \\
\hline C23 & 0.4804 & 0.3664 & 0.2710 & \\
\hline $\mathrm{C} 24$ & 0.3935 & 0.4097 & 0.2981 & \\
\hline $\mathrm{C} 25$ & 0.3089 & 0.3777 & 0.3534 & \\
\hline $\mathrm{C} 26$ & 0.3112 & 0.3023 & 0.3816 & \\
\hline C31 & $0.6907 \pm 6$ & $0.6096 \pm 3$ & $010901 \pm 4$ & $5.20 \pm 19$ \\
\hline C32 & $0.7063^{\perp-}$ & 0.6048 & 0.1754 & \\
\hline C33 & 0.6131 & 0.5773 & 0.2259 & \\
\hline C34 & 0.5042 & 0.5547 & 0.1912 & \\
\hline C35 & 0.4887 & 0.5595 & 0.1059 & \\
\hline C35 & 0.4887 & 0.5595 & 0.1059 & \\
\hline C36 & 0.5819 & 0.5870 & 0.0553 & \\
\hline C41 & $1.0208 \pm 5$ & $0.1613 \pm 4$ & $0.4303 \pm 5$ & $7.11 \pm 23$ \\
\hline $\mathrm{C42}$ & 0.9768 & 0.2246 & 0.4663 & \\
\hline $\mathrm{C43}$ & 0.9571 & 0.2879 & 0.4178 & \\
\hline C44 & 0.9814 & 0.2880 & 0.3333 & \\
\hline C45 & 1.0254 & 0.2247 & 0.2973 & \\
\hline C46 & 1.0451 & 0.1614 & 0.3457 & \\
\hline C51 & $0.9241 \pm 6$ & $0.4526 \pm 4$ & $0.3353 \pm 3$ & $6.04 \pm 20$ \\
\hline C52 & 1.0137 & 0.5107 & 0.3530 & \\
\hline C53 & 0.9918 & 0.5734 & 0.4018 & \\
\hline C54 & 0.8804 & 0.5779 & 0.4330 & \\
\hline C55 & 0.7809 & 0.5198 & 0.4153 & \\
\hline C56 & 0.8127 & 0.4572 & 0.3665 & \\
\hline C61 & $0.6621 \pm 6$ & $0.3154 \pm 4$ & $0.0703 \pm 4$ & $6.25 \pm 22$ \\
\hline $\mathrm{C} 62$ & 0.6939 & 0.2556 & 0.1194 & \\
\hline $\mathrm{C63}$ & 0.7774 & 0.2709 & 0.1812 & \\
\hline C64 & 0.8291 & 0.3461 & 0.1939 & \\
\hline $\mathrm{C65}$ & 0.7973 & 0.4060 & 0.1447 & \\
\hline C66 & 0.7138 & 0.3907 & 0.0829 & \\
\hline
\end{tabular}


Better accuracy in structural details was obtained by means of a leastsquares refinement of the paramters using a rigid group program. ${ }^{5}$ The number of parameters was then reduced to 77 which gives a more favourable ratio between the number of reflections and the number of parameters. After a few cycles, when the parameter shifts were less than $5 \%$ of the standard deviations, the refinement was considered complete.

Scheringer's weighting function

$$
w=\left(\Delta^{2}+4.0\right)^{-1} \text { where } \Delta=|| F_{\text {obs }}|-| F_{\text {calc }} \|
$$

was used in the refinement. The positional parameters and the isotropic temperature factors are given in Table 2 together with the standard deviations which are throughout smaller than those obtained from the preliminary refinement described above. This is considered to indicate that the data given in Table 2 represent the better description of the molecular structure.

However, the discrepancy index $R$ comes out as 0.14 for both procedures of refinement.

The calculated interatomic distances and their standard deviations are given in Table 3. All distances lie within normal ranges, thus supporting the correctness of the coordinates arrived at in the last cycle.

Table 3. Interatomic distances $(\AA)$ and standard deviations $( \pm \sigma$ in $\AA$ ) and some angles in $\left[\left(\mathrm{C}_{6} \mathrm{H}_{5}\right)_{3} \mathrm{Si}\right]_{2} \mathrm{CrO}_{4}$. The distances are uncorrected for thermal motion.

$\begin{array}{ll}\mathrm{Cr}-\mathrm{O1} & 1.782 \pm 10 \\ \mathrm{Cr}-\mathrm{O} 2 & 1.706 \pm 10 \\ \mathrm{Cr}-\mathrm{O3} & 1.568 \pm 12 \\ \mathrm{Cr}-\mathrm{O4} & 1.514 \pm 13 \\ \mathrm{Sil}-\mathrm{O} 1 & 1.601 \pm 11 \\ \mathrm{Si2}-\mathrm{O} 2 & 1.605 \pm 11 \\ \mathrm{Sil}-\mathrm{C} 11 & 1.897 \pm 8 \\ \mathrm{Sil}-\mathrm{C} 24 & 1.939 \pm 8 \\ \mathrm{Sil}-\mathrm{C} 34 & 1.847 \pm 8 \\ \mathrm{Si} 2-\mathrm{C} 44 & 1.861 \pm 8 \\ \mathrm{Si} 2-\mathrm{C} 51 & 1.852 \pm 8 \\ \mathrm{Si} 2-\mathrm{C} 64 & 1.856 \pm 8\end{array}$

$$
\begin{aligned}
& \mathrm{O} 2-\mathrm{Cr}-\mathrm{O} 1 \quad 111.22 \pm 46^{\circ} \\
& \mathrm{O} 1-\mathrm{Cr}-\mathrm{O} 3 \quad 108.43 \pm 53 \\
& \mathrm{O} 1-\mathrm{Cr}-\mathrm{O} 4 \quad 107.44 \pm 60 \\
& \mathrm{O} 2-\mathrm{Cr}-\mathrm{O} 3 \quad 108.67 \pm 55 \\
& \mathrm{O} 2-\mathrm{Cr}-\mathrm{O} 4 \quad 112.06 \pm 60 \\
& \mathrm{O} 3-\mathrm{Cr}-\mathrm{O} 4 \quad 108.93 \pm 66 \\
& \mathrm{Cr}-\mathrm{O} 1-\mathrm{Sil} \quad 133.06 \pm 58^{\circ} \\
& \mathrm{Cr}-\mathrm{O} 2-\mathrm{Si} 2 \quad 162.71 \pm 67 \\
& \text { O1 - Sil-Cll } \quad 106.05 \pm 44^{\circ} \\
& \mathrm{Ol}-\mathrm{Sil}-\mathrm{C} 24 \quad 108.79 \pm 43 \\
& \mathrm{O} 1 \text {-Sil-C34 } \quad 107.26 \pm 46 \\
& \text { C11-Sil-C24 } \quad 109.79 \pm 35 \\
& \mathrm{C} 11-\mathrm{Sil}-\mathrm{C} 34 \quad 109.26 \pm 34 \\
& \text { C24-Sil-C34 } 115.27 \pm 34 \\
& \mathrm{O} 2-\mathrm{Si} 2-\mathrm{C} 44 \quad 105.15 \pm 44^{\circ} \\
& \mathrm{O} 2-\mathrm{Si2}-\mathrm{C} 51 \quad 108.50 \pm 45 \\
& \mathrm{O}^{1}-\mathrm{Si2}-\mathrm{C} 64 \quad 110.72 \pm 47 \\
& \text { C44-Si2-C51 } \quad 108.35 \pm 37 \\
& \mathrm{C} 44-\mathrm{Si} 2-\mathrm{C} 64 \quad 112.58 \pm 36 \\
& \begin{array}{ll}
\mathrm{C} 51-\mathrm{Si} 2-\mathrm{C} 64 & 111.27 \pm 37
\end{array}
\end{aligned}
$$

A list of the observed and calculated structure factors is presented in Table 4.

In the unit cell there are also 120 hydrogen atoms. It was not possible to determine their parameters from the present set of experimental data.

Acta Chem. Scand. 24 (1970) No. 1 
Table 4. Observed and calculated structure factors for $\left[\left(\mathrm{C}_{6} \mathrm{H}_{5}\right)_{3} \mathrm{Si}_{2} \mathrm{CrO}_{4}\right.$.
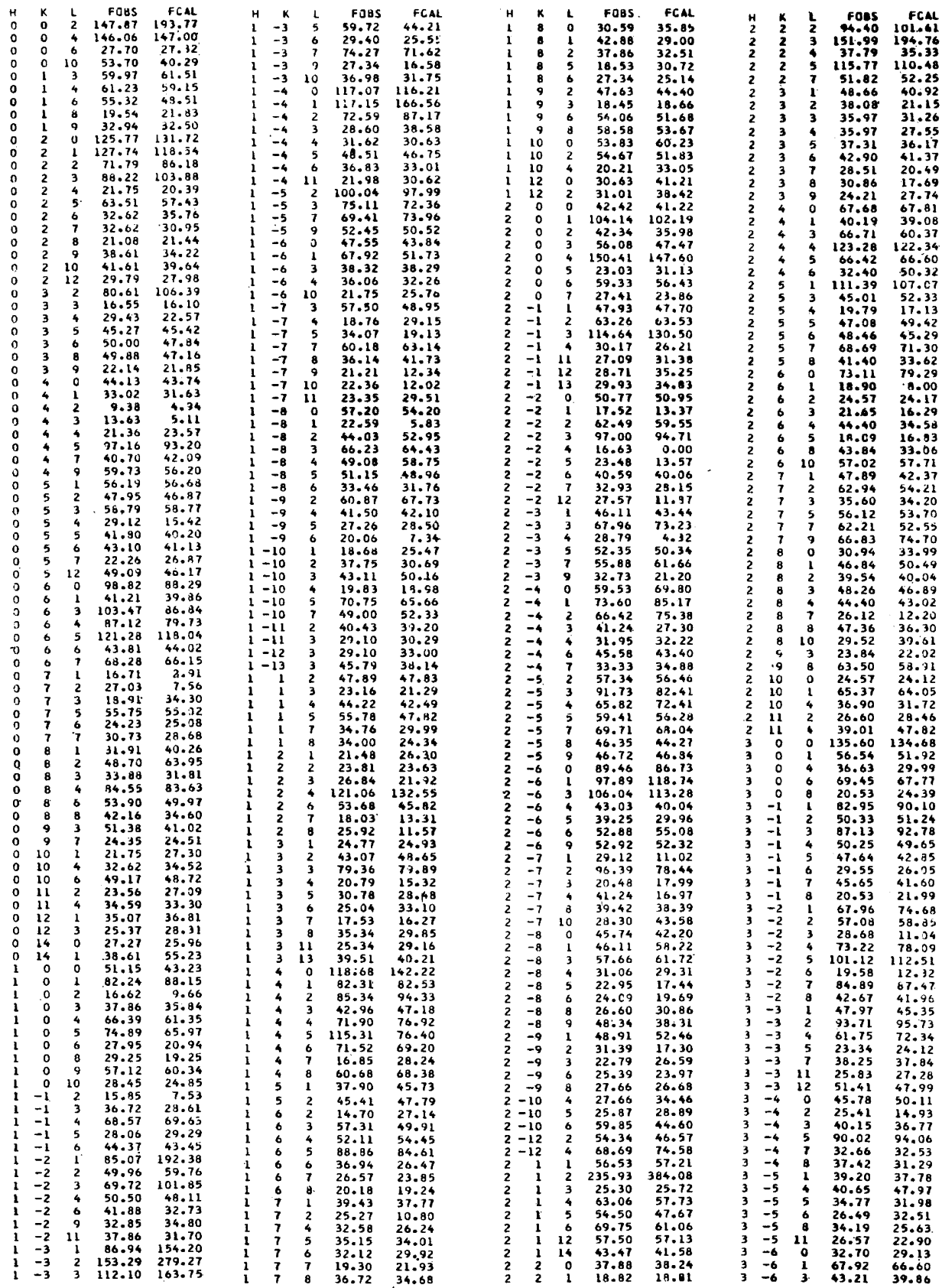

Acta Chem. Scand. 24 (1970) No. 1 
Table 4. Continued.

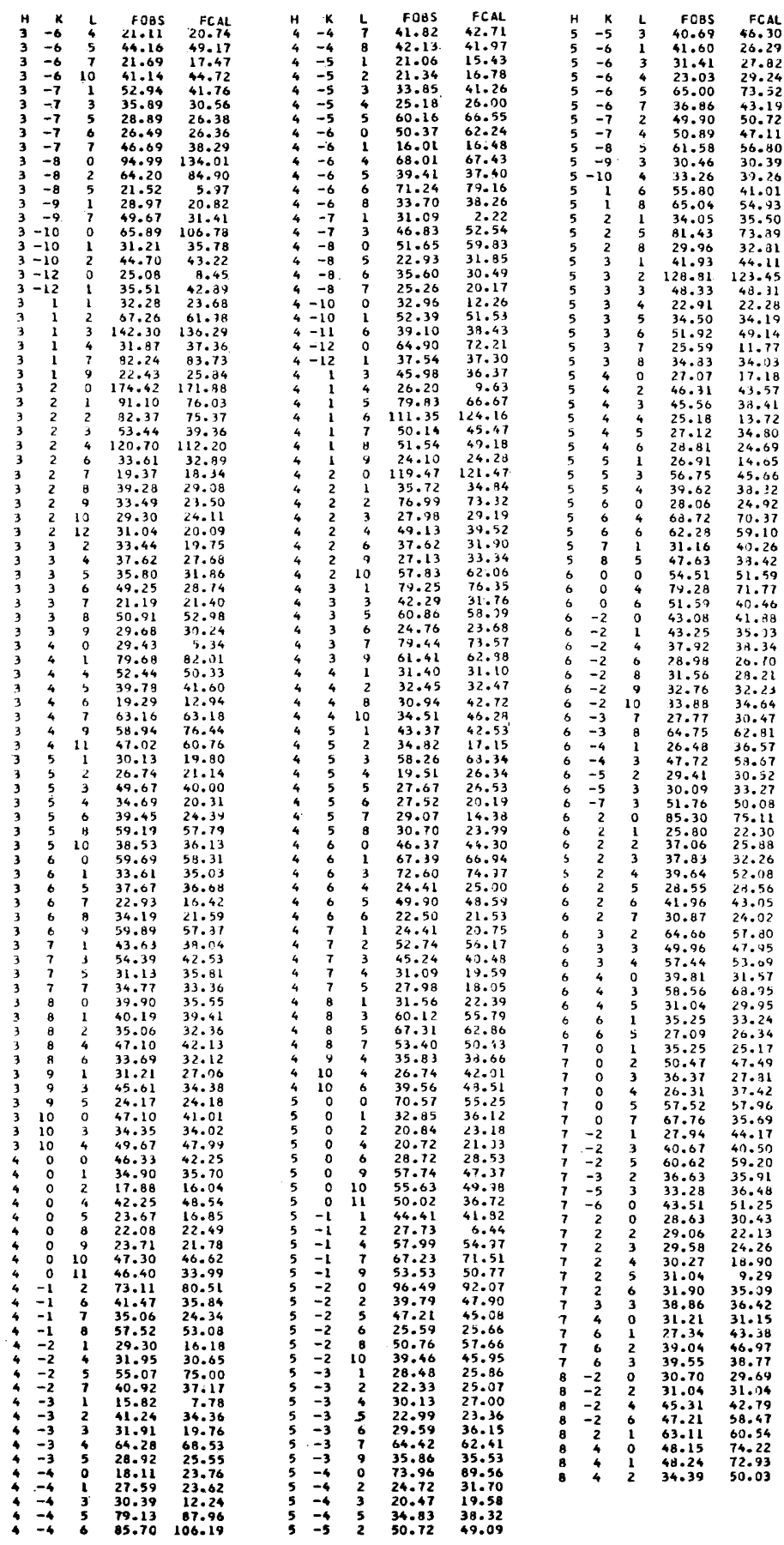




\section{DESCRIPTION AND DISCUSSION OF THE STRUCTURE}

The crystals of $\left[\left(\mathrm{C}_{6} \mathrm{H}_{5}\right)_{3} \mathrm{Si}\right]_{2} \mathrm{CrO}_{4}$ are built up of molecules, each of which is formed by a $\mathrm{CrO}_{4}$ tetrahedron which is linked to the silicon atoms by oxygen bridges. In addition to the oxygen contact each silicon atom is also in contact with three aromatic rings which project from it like propeller blades. Schematic drawings of the molecule and the packing of the molecules in the unit cell are shown in Figs. 1-2.

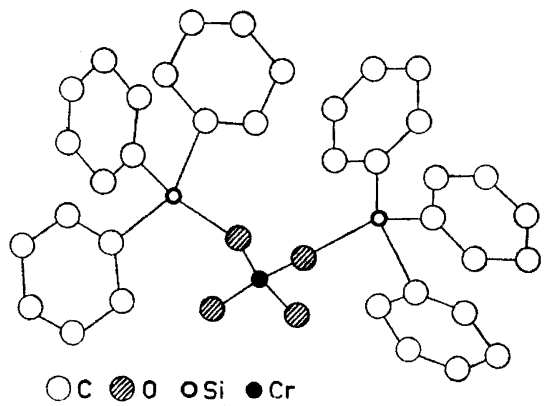

Fig. 1a. The molecular configuration of $\left[\left(\mathrm{C}_{6} \mathrm{H}_{5}\right)_{3} \mathrm{Si}_{2} \mathrm{CrO}_{4}\right.$.

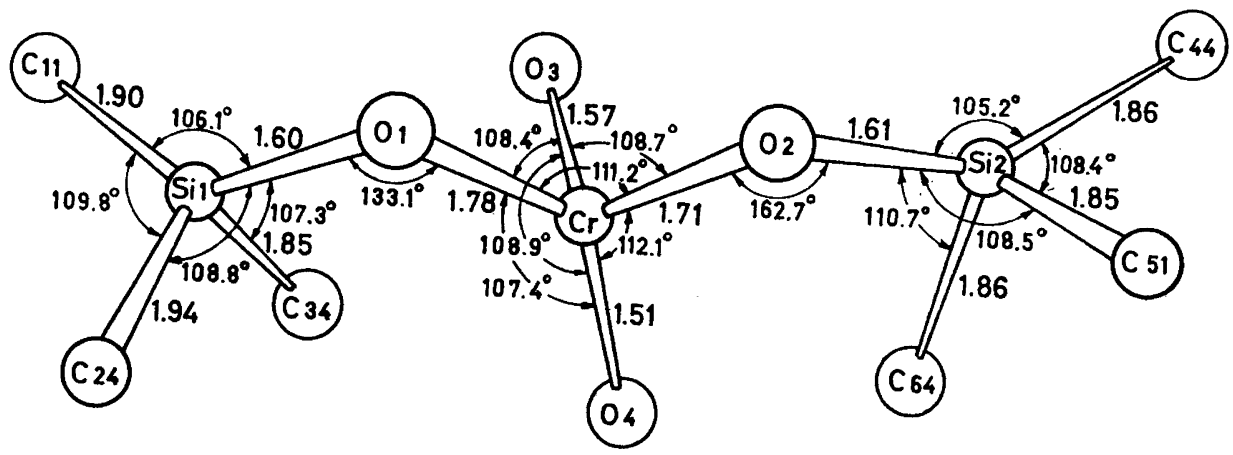

Fig. 1b. Bond lengths and bond angles within the $\left[\left(\mathrm{C}_{6} \mathrm{H}_{5}\right)_{3} \mathrm{Si}_{2}\right]_{2} \mathrm{CrO}_{4}$ molecule.

The interatomic distances ( $c f$. Table 3 ) within the molecule are, as mentioned above, all within the normal ranges. The average $\mathrm{Cr}-\mathrm{O}$ distance within the $\mathrm{CrO}_{4}$ group is $1.64 \AA$ and the average angle $\mathrm{O}-\mathrm{Cr}-\mathrm{O}$ is $109.5^{\circ}$. These values are in good agreement with those found in other chromates. ${ }^{10}$ However, two $\mathrm{Cr}-\mathrm{O}$ distances are much longer (average value of $1.74 \AA$ ) than the remaining two in the $\mathrm{CrO}_{4}$ tetrahedron (average value of $1.54 \AA$ ). The former represent the bridge oxygens. 


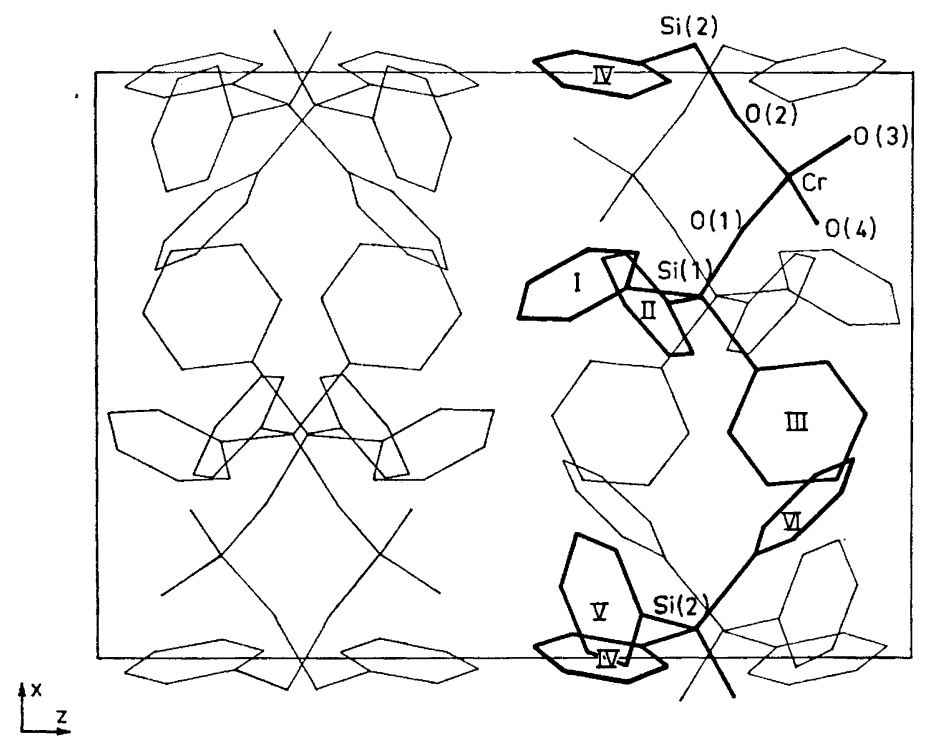

Fig. 2. Schematic drawing of the structure of $\left[\left(\mathrm{C}_{6} \mathrm{H}_{5}\right)_{3} \mathrm{Si}\right]_{2} \mathrm{CrO}_{4}$ projected on the $x z$ plane. The Roman numerals denote the six aromatic rings.

The $\mathrm{Si}-\mathrm{O}$ and $\mathrm{Si}-\mathrm{C}$ distances found (the average values are $1.60 \AA$ and $1.88 \AA$ ) are in concordance with the values 1.59 to $1.63 \AA$ (average 1.612 $\AA$ ) for $\mathrm{Si}-\mathrm{O}$ and $1.84 \pm 1 \AA$ for $\mathrm{Si}-\mathrm{C}$, obtained from a large number of determinations given in the International Tables. ${ }^{9}$

The aromatic rings, assumed in the refinement to be planar with carboncarbon distances equal to $1.395 \AA$, are twisted relative to each other. The angle between adjacent phenyl rings is $74.1^{\circ}$ (average value of six angles). This is somewhat bigger than the values $47-54^{\circ}$, estimated on the basis of steric considerations ${ }^{11}$ and the values $\left(54.3^{\circ}\right)$ reported for triphenylmethyl perchlorate by Gomes de Mesquita, MacGillavry and Eriks.12 Larger valuès ranging from $62^{\circ}$ to $112^{\circ}$ have been published for tristriphenylphosphine rhodium carbonyl hydride by La Placa and Ibers. ${ }^{13}$

Acknowledgements. This investigation has received financial support from the Swedish Natural Science Research Council and from the Tri-Centennial Fund of the Bank of Sweden. Permission for the use of the computers Facit EDB and CD 3600 was granted by the Computer Division of the National Swedish Rationalization Agency. The use of the IBM 7090 was made possible through the Northern Europe University Computing Center.

The authors warmly thank Professor Arne Magnéli for his encouraging and stimulating interest and for all facilities placed at our disposal. We are also indebted to Dr. PerErik Werner for his willing and invaluable help in adapting Scheringer's rigid-body program for the IBM 7090 computer. Thanks are also due to Dr. Sven Westman for his correction of the English of this paper. 


\section{REFERENCES}

1. Granchelli, F. E. and Walher, G. B. US Patent 2,863, 891, Dec. 9, 1968.

2. Hambling, P. G. Acta Cryst. 6 (1853) 98.

3. Werner, P.-E. To be published.

4. Leijonmarck, M. Univ. Stockholm, Inorg. and Phys. Chem. DIS No. 33.

5. Scheringer, C. Private communication.

6. Norrestam, R. Univ. Stockholm, Inorg. and Phys. Chem. DIS No. 33.

7. IUCr World List of Crystallographic Computer Programs, 2nd Ed., July 1966.

8. Dauben, C. H. and Templeton, D. H. Acta Cryst. 8 (1955) 841.

9. International Tables for $X$-ray Crystallography, Kynoch Press, Birmingham 1962, Vol. III.

10. Wilhelmi, K.-A., Diss., Stockholm 1966.

11. Deno, N. C., Jaruzelski, J. J. and Schriesheim, A. J. Org. Chem. 19 (1954) 155.

12. Gomes de Mesquita, H., MacGillavry, C. H. and Eriks, K. Acta Cryst. 18 (1965) 437.

13. La Placa, S. J. and Ibers, J. A. Acta Cryst. 18 (1965) 511.

Received July 8, 1969. 